fine themselves rigidly to it; they present a carefully balanced account of the known pharmacological effects of each drug, and are at pains not to overemphasize those actions that fit in with the general notion. Finally, the authors briefly discuss the drugs currently used to treat tremor.

No similar comprehensive contemporary monograph on tremor exists and this book will serve as a useful reference to the many scientists who have tried to unravel the mystery of tremor. However, it is more a progress report than a definitive work, for, as the authors conclude, 'It has become increasingly clear during the preparation of this monograph that any attempt to draw generalised conclusions concerning tremor, whether normal or disease-or drug-induced, is doomed to failure'. Future work, helped and perhaps prompted by this book, may allow the authors to modify this conclusion.

\section{D. MARSDEN}

ESSENTIALS OF THE NEUROLOGICAL EXAMINATION By

Bernard J. Alpers, and Elliott L. Mancall. (Pp. 173; illustrated; $£ 2 \cdot 50$.) Blackwell Scientific Pub-

lications: Oxford; and Davis: Philadelphia. 1971. This is in general a good book, well and clearly written, and by American standards good value for money. Despite the fact that according to the authors it has been reduced to the bare essentials of neurological examination, it is very comprehensive. I can make only minor criticisms: no mention is made of Beevor's sign, despite long lists containing some less valuable signs and reflexes. The differences between voluntary and reflex lateral gaze paralysis is not clearly described. In a book of this size and nature no mention is made of tumour diagnosis and I could find no reference to false localizing signs. Twelve pages are devoted to aphasia and associated phenomena, but the brain-stem reticular substance is not mentioned once. The positive signs of hysteria deserve a fuller account.

A valuable bench book for the wards, but possibly too comprehensive for the undergraduate student.

J. H. D. MILlAR

CEREBRAL BLOOD FLOW Edited by J. S. Meyer and

J. P. Schadé. (Pp. 437; illustrated; ca. \$32.75.)

Elsevier: Amsterdam. 1972.

A competition for the least helpful book on the cerebral circulation would be a close run race these days. Many have been conference proceedings with all the limitations which these impose on the composition of a coherent account of any subject. But this book was planned by two editors, who invited contributors to write on specific topics. If the editors had a plan in their minds they have covered up their tracks skilfully, and as they do not even write a pre- face they are not tempted to give away any clues. There are chapters on related topics which present different, and sometimes conflicting, views, but such chapters do not even appear beside each other. The book begins with two idiosyncratic methods of measuring blood flow, one from Japan and one from Bulgaria; as one of these authors has 14 references and the other 27 references to himself, each is obviously advancing a rather personal view. Other fringe methods are described, but nowhere do the editors attempt to put this complex subject in perspective. Scattered through the book are animal studies and clinical investigations of either normal or abnormal blood flow, in between random eruptions of pure methodology. There are a few good chapters, but their authors must be embarrassed to find the context in which they appear. After about a decade of measuring cerebral blood flow a critical appraisal of the state of the art is badly needed. It is a pity that the effort and energy of so many in this field was wasted on this disorganized book, and the opportunity lost for a responsible stocktaking.

BRYAN JENNETT

THE FORMATION OF NERVE CONNECTIONS By R. M.

Gaze. (Pp. 288; illustrated; £4.) Academic Press: London. 1970.

One must admire the courage of an author who tackles a central problem of neurobiology at a time when the jigsaw will not fall into place. It has taken a long time to review because it is extremely difficult to carry the argument(s) marshalled from one short sampling period to the next because Dr. Gaze starts out with one theory, follows it to the point of failure, and then abandons it to start anew. Drawing his evidence from the innervation of muscle, skin, and eye, the author examines the connections between neurones. Are they predetermined genetically or are they induced by functional requirements on a chemoaffinity basis? There may be no simple answer, both mechanisms seem to occur in the nervous system. If the conclusions hint at a neurological indeterminancy principle this book will be an invaluable guide to strategy for future experimenters.

J. A. SIMPSON

ASPECTS OF THE EPIDEMIOLOGY OF MENTAL ILLNESS: STUDIES IN RECORD LINKAGE Edited by J. A. Baldwin. (Pp. 226; £4.50.) Churchill Livingstone: Edinburgh. 1972.

This volume describes the creation of a recordlinkage system which made possible the maintenance of a cumulative index of all patient contacts with the psychiatric services in North-East Scotland, a region based on the city of Aberdeen, and its medical school. Dr. J. A. Baldwin was responsible for the 